\title{
Aplicação do aço carbono e ferro Armco na produção de gás hidrogênio em ácido fórmico
}

\author{
Application of carbon steel and Armco iron \\ in the production of hydrogen gas in formic acid
}

\author{
André Lazarin Gallina ${ }^{1}$, Ana Paulo Camargo Matheus ${ }^{2}$, \\ Bianca Vanjura Dias ${ }^{2}$, Marilei Fátima de Oliveira ${ }^{3}$, \\ Paulo Rogério Pinto Rodrigues ${ }^{2}$
}

\footnotetext{
${ }^{1}$ Departamento de Química - Universidade Federal da Fronteira Sul - UFFS - Rodovia PR-182 Km 466, s/n, Realeza, PR. e-mail: andre.gallina@uffs.edu.br

${ }^{2}$ Grupo de Pesquisa em Eletroquímica - GPEL® - DEQ/UNICENTRO - CEP: 85040-080, Guarapuava, PR. e-mail: aninhacamargo.matheus@gmail.com,biavanjura@yahoo.com.br, prprodrigues@unicentro.br

${ }^{3}$ Departamento de Engenharia Mecânica - UTFPR - Avenida Professora Laura Pacheco Bastos, nº00, Bairro Industrial, 85053-510 Guarapuava - Paraná, Brasil.

e-mail: ofmarilei@gmail.com
}

\section{RESUMO}

Os incentivos às políticas energéticas e as atuais exigências ambientais motivam a busca por fontes de energia alternativa, como o gás hidrogênio. Este trabalho tem como objetivo a produção do gás hidrogênio via eletrólise do ácido fórmico, utilizando eletrodos de aço carbono 1008 e ferro Armco. Os ensaios foram feitos mediante planejamento experimental, e empregaram-se as técnicas de microscopia óptica, polarização potenciodinâmica catódica, potencial de circuito aberto e cronoamperometria. Os resultados mostraram que o tratamento da superfície dos eletrodos com lixa de carbeto silício (SiC) \#320 é eficiente quando comparada aos outros tratamentos testados, para o desprendimento de $\mathrm{H}_{2}$. O ferro Armco, apresentou maior produção de hidrogênio, em média $70 \%$ a mais quando comparado com a platina em ambos os meios estudados, entretanto sua vida útil é menor.

Palavras-chave: biomassa, catalisador, biocombustível.

\section{ABSTRACT}

Incentives for energy policies and current environmental requirements motivate the search for alternative energy sources such as hydrogen gas. This paper aims at the production of hydrogen gas via electrolysis of formic acid using electrodes of 1008 carbon steel and Armco iron. Samples were done by experimental design, and employed the techniques of optical microscopy, cathodic potentiodynamic polarization, open circuit potential and chronoamperometry. The results showed that the surface treatment of the electrodes with \#320 grit $\mathrm{SiC}$ abrasive paper is effective when compared to the other treatments tested for the evolution of $\mathrm{H}_{2}$. The Armco iron, showed higher hydrogen production, on average $70 \%$ increased when compared with platinum in both studied media, however its lifetime is shorter.

Keywords: biomass, catalyst, biofuel.

\section{INTRODUÇÃO}

A dependência energética mundial e a supervalorização econômica do petróleo ao longo dos anos, associado à grande produção de $\mathrm{CO}_{2}$, servem como alerta para a busca de fontes alternativas de energia [1-3]. O Brasil, mesmo com sua matriz energética diversificada começou a investir em energias oriundas da biomassa (biodiesel e etanol de cana de açúcar) e mais recentemente no hidrogênio [4-5].

O gás hidrogênio ainda não participa da matriz energética nacional, porém o governo brasileiro consi- 
dera a produção deste gás uma de suas áreas estratégicas relacionadas à energia. Para que isto ocorra, desde 2005 foram feitos estudos pelo Centro de Gestão e Estudos Estratégicos (CGEE) e como fruto destes estudos foi elaborado no ano de 2010 um documento técnico, que relata os principais gargalos tecnológicos da cadeia produtiva do gás hidrogênio, visando à sua inserção na matriz energética, em curto/médio prazo, para o período de 2010 a 2025 [6].

O hidrogênio é um combustível limpo, ou seja, não produz nenhum gás de efeito estufa em sua combustão, e tem sido considerado um promissor combustível sustentável para o fornecimento de energia, desde que produzido a partir de fontes renováveis, como coprodutos agrícolas, resíduos florestais e de biocombustíveis que a priori não tenham grande mercado, e que estejam sendo estocados ou descartados [7-9].

A produção de hidrogênio pode ocorrer por vários processos, como: gaseificação, processos fotobiológicos, eletrólise da água, produção via reforma do etanol e gás natural.

O processo de gaseificação consiste na combinação de processos termoquímicos: combustão, pirólise e gaseificação, ocorrendo em um gaseificador com produção de um gás contendo $\mathrm{CO}(\mathrm{g}), \mathrm{CO}_{2}(\mathrm{~g}), \mathrm{H}_{2}(\mathrm{~g}), \mathrm{CH}_{4}(\mathrm{~g})$ $[6,10-14]$.

Os processos fotobiológicos utilizam micro-organismos, que realizam fotossíntese para obtenção de hidrogênio. Sua maior vantagem é a produção limpa do combustível [6, 15-18].

A eletrólise da água consiste na passagem de eletricidade para a quebra da molécula de água, para geração do hidrogênio e oxigênio. Este processo possui um rendimento que pode chegar a $95 \%$ e não há emissão de poluentes [6,12,19-21].

A produção via reforma do etanol poderia produzir milhões de toneladas de hidrogênio, se levado em consideração à quantidade de etanol de primeira geração produzido no Brasil [18]. Este fato é devido à infraestrutura já consolidada do etanol, sendo possível a produção do hidrogênio de forma renovável. Entretanto, o uso desta tecnologia ainda encontra-se em estágio embrionário no Brasil, e a produção de hidrogênio a partir da reforma do etanol é utilizada somente em pesquisas acadêmicas [22].

A reforma do gás natural pode ser considerada uma alternativa mais competitiva para produção do gás hidrogênio, pela disponibilidade, tecnologia empregada, e pela reforma auto térmica ou do vapor, pois já são empregados no setor petroquímico [23].

A eletrólise da água é o processo mais simples dentre os mencionados, porém depende de inúmeras variáveis (eletrodo, eletrólito e catalisadores) que influenciam consideravelmente na quantidade de energia empregada, e consequentemente no custo de produção [24]. Desta forma torna-se necessário o estudo para otimização destas variáveis.

Atualmente, são estudadas soluções eletrolíticas derivadas da biomassa, como o ácido fórmico, ácido acético, entre outros para minimizar a energia empregada no processo de produção de hidrogênio. O ácido fórmico é um dos produtos gerados na produção do bio-óleo, desta maneira o custo de produção do mesmo é relativamente baixo, pois é obtido da pirólise da biomassa [25]. Soluções de ácido fórmico podem ser utilizadas para a produção de gás hidrogênio eletroquimicamente empregando eletrodos sólidos. A energia envolvida é relativamente baixa quando comparada a eletrólise da água, ou seja, uma interessante economia pode ser obtida [26-29].

Com relação aos catalisadores, estão sendo empregadas moléculas conhecidas como inibidores de corrosão, que em baixas concentrações podem catalisar a reação de desprendimento de hidrogênio na superfície do eletrodo, dentre estes os compostos orgânicos da família dos azóis, como o benzotriazol (BTAH). Estudos realizados por Rodrigues (1997) mostraram que o efeito inibidor esta relacionado com a concentração do mesmo, visto que em concentrações abaixo de $10^{-3} \mathrm{~mol} \mathrm{~L}^{-1}$, há catálise das reações de oxidação e redução na superfície metálica, para um sistema com aço carbono e ácido sulfúrico $2 \mathrm{~mol} \mathrm{~L}^{-1}$. [29-34].

Para a produção de hidrogênio via eletrólise da água são utilizados eletrodos de platina, porém o custo é extremamente elevado por se tratar de um metal nobre, desta maneira estudos com ligas de ferro como eletrodos estão ganhando espaço entre as pesquisas relacionadas com a produção de hidrogênio, pois apresentam menor custo quando comparados com a platina além de serem produzidos em grande escala.

O objetivo deste trabalho é estudar o uso de eletrodos de ligas de ferro em ácido fórmico $3 \mathrm{~mol} \mathrm{~L}^{-1}$ na presença e ausência de BTAH para a produção de gás hidrogênio. 


\section{MATERIAIS E MÉTODOS}

\subsection{Soluções empregadas}

Soluções de ácido fórmico $\left(\mathrm{CH}_{2} \mathrm{O}_{2}\right)$ : estas soluções foram preparadas com água bidestilada e reagentes de pureza analítica (P.A.) na concentração de $3 \mathrm{~mol} \mathrm{~L}^{-1}$, tal concentração foi escolhida devido a trabalhos encontrados na literatura [26], além de estudos prévios feito pelo autores.

Soluções de ácido fórmico + BTAH: Foram preparadas com água bidestilada e reagentes de pureza analítica (P.A.). As concentrações de BTAH foram de $1.10^{-6}, 1.10^{-8}, 1.10^{-10} \mathrm{~mol} \mathrm{~L}^{-1}$, em ácido fórmico $3 \mathrm{~mol} \mathrm{~L}^{-1}$.

\subsection{Eletrodos empregados}

Eletrodo Auxiliar: Utilizou-se um eletrodo de platina com uma área de aproximadamente $25 \mathrm{~cm}^{2}$.

Eletrodo de Referência: Eletrodo de Prata/Cloreto de Prata $\left(\mathrm{Ag}_{(\mathrm{s})}\left|\mathrm{AgCl}_{(\mathrm{s})}\right| \mathrm{KCl} 3 \mathrm{~mol} \mathrm{~L}^{-1}\right)$, acoplado de um capilar de Luggin.

Eletrodos de Trabalho: Foram utilizados diversos tipos e formas de eletrodos de trabalho, devido aos objetivos deste trabalho, como segue: Platina (98,8\% Pt): 3,16 $\mathrm{cm}^{2}$; Aço Carbono 1008 (98,45\%): $3,16 \mathrm{~cm}^{2}$; Ferro Armco (99,56\% Fe): 0,985 $\mathrm{cm}^{2}$.

\subsection{Polimentos}

Foi realizado o polimento dos eletrodos metálicos utilizando lixas de carbeto de silício (SiC) \#320, \#1200 e pasta de diamante com partículas de $9 \mu \mathrm{m}, 6 \mu \mathrm{m}, 3 \mu \mathrm{m}$ e $1 \mu \mathrm{m}$ de diâmetro, com o intuito de verificar a relação entre o polimento e o desprendimento de gás hidrogênio.

\subsection{Célula Eletroquímica}

Célula eletrolítica, figura 1: Consiste de uma célula de vidro com capacidade de aproximadamente $30 \mathrm{~mL}$, com um capilar de Luggin como reservatório para o eletrodo de referência. Esta célula foi empregada nos ensaios de polarização potenciodinâmica catódica $(\mathrm{PC})$, cronoamperometria $(\mathrm{CR})$, e potencial de circuito aberto $\left(\mathrm{E}_{\mathrm{CA}}\right)$, todos realizados com eletrodo estático.

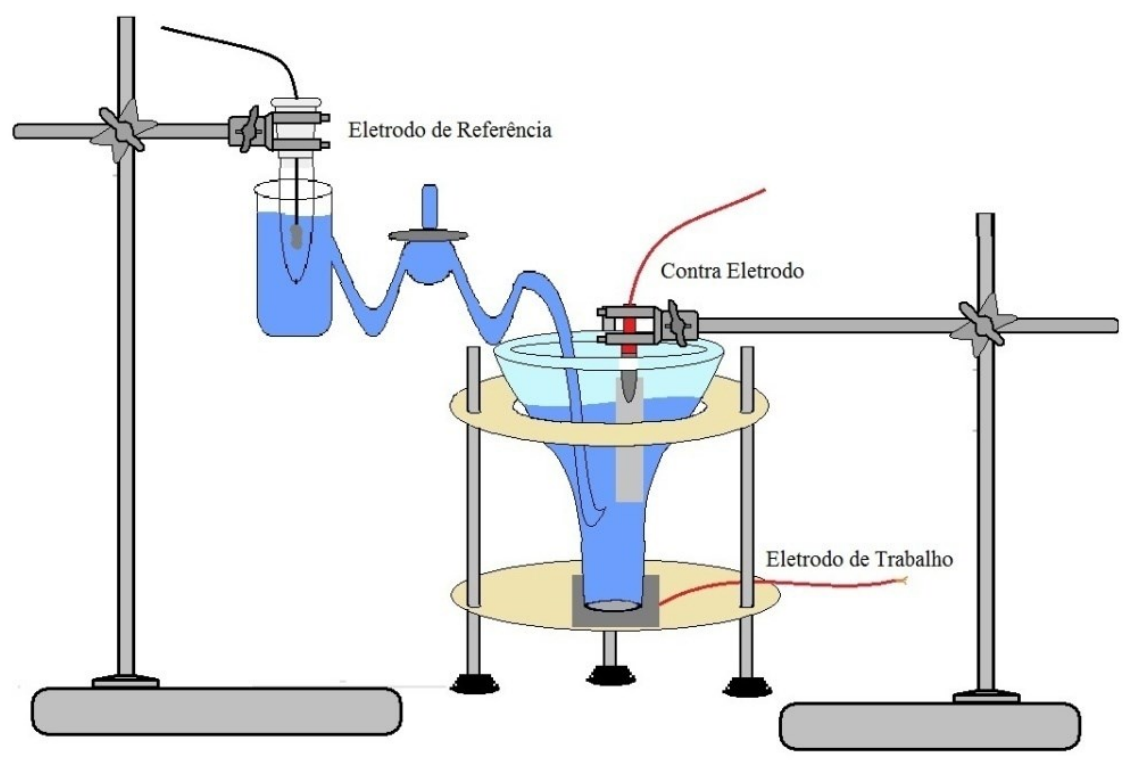

Figura 1: Desenho esquemático da célula eletroquímica empregada. 


\subsection{Equipamentos}

\section{Potenciostato:}

Foi utilizado um potenciostato marca Gamry, modelo PC4-300, para os ensaios de eletroquímicos.

\section{Voltímetros:}

Nas medidas de potencial de circuito aberto utilizou-se um voltímetro digital de 31/2 dígitos da marca Minipa, após a estabilização do potencial a célula foi ligada ao potenciostato para o restante das medidas.

\section{Politriz:}

Para o polimento dos eletrodos de trabalho foi utilizado uma politriz da marca Arotec, modelo APL-2.

\subsection{Ensaios Eletroquímicos}

\section{Curvas de Polarização Potenciodinâmica Catódica (PPC) :}

Para o estudo da reação de desprendimento de hidrogênio foi utilizada a polarização potenciodinâmica catódica, aplicando-se uma sobrepotencial de $-1,150 \mathrm{~V}$ em relação ao potencial de circuito aberto, contra o eletrodo de referência. A velocidade de varredura (v.v.) utilizada foi de $1 \mathrm{mV} \mathrm{s}^{-1}$.

\section{Cronoamperometria $(\mathrm{CR})$ :}

No estudo da reação de desprendimento de hidrogênio a cronoamperometria foi realizada com uma sobrepotencial de $-1,150 \mathrm{~V}$ em relação ao potencial de circuito aberto, contra o eletrodo de referência de $\mathrm{Ag}_{(\mathrm{s})}\left|\mathrm{AgCl}_{(\mathrm{s})}\right| \mathrm{KCl} 3 \mathrm{~mol} \mathrm{~L}^{-1}$, durante um período de $600 \mathrm{~s}$, os resultados deste ensaio foram utilizados para o cálculo da quantidade de gás hidrogênio produzido, através do uso das densidades de corrente no intervalo de 100 a 600 s.

\section{Espectroscopia de Impedância Eletroquímica (EIE):}

Os diagramas de EIE na forma de Nyquist e Bode foram realizadas no $\mathrm{E}_{\mathrm{CA}}$, no modo potenciostático com uma perturbação de $\mathrm{E}= \pm 10 \mathrm{mV} \mathrm{rms}$, para a faixa de frequência de $10 \mathrm{kHz}$ a $0,01 \mathrm{~Hz}$. Os pontos foram registrados 10 pontos por década de frequência.

\section{Condições de ensaio:}

Os ensaios foram realizados na temperatura de $25^{\circ} \pm 2^{\circ} \mathrm{C}$, em duplicata, caso a diferença entre as medidas fosse superior a $5 \%$, realizava-se a triplicata.

\subsection{Ensaios de Microscopia Óptica}

As micrografias dos eletrodos de trabalho utilizados no estudo foram feitas por meio de uma máquina fotográfica marca MediaCybernetics ${ }^{\circledR}$, modelo Evolution LC Color, acoplada a um microscópio marca Olympus, modelo BX41M. As imagens foram obtidas com aumento de 100 vezes.

\subsection{Quantificação do gás Hidrogênio}

A quantificação do gás hidrogênio foi realizada utilizando-se as Leis de Faraday, os valores de corrente e tempo utilizados foram obtidos dos ensaios de cronoamperometria, nos intervalos de tempo de $100 \mathrm{~s}-600 \mathrm{~s}$. Além deste método para quantificação utilizou-se um equipamento da marca Honeywell ${ }^{\circledR}$ modelo EC-P2.

\section{RESULTADOS}

\subsection{Efeito do tratamento da superfície do eletrodo na produção de hidrogênio}

Primeiramente foi avaliado a influência do tratamento da superfície (TS) dos metais, em relação a rugosidade do mesmo, realizando o polimento dos eletrodos com lixas de carbeto de silício ( $\mathrm{SiC}$ \#1200 e \#320 e com pasta de diamante com partículas de $1 \mu \mathrm{m}$ de diâmetro. 
Na figura 2, são apresentadas as curvas de polarização dos eletrodos de ligas de ferro e a platina, em ácido fórmico $3 \mathrm{~mol} \mathrm{~L}^{-1}$, com diferentes tratamentos de superfície.

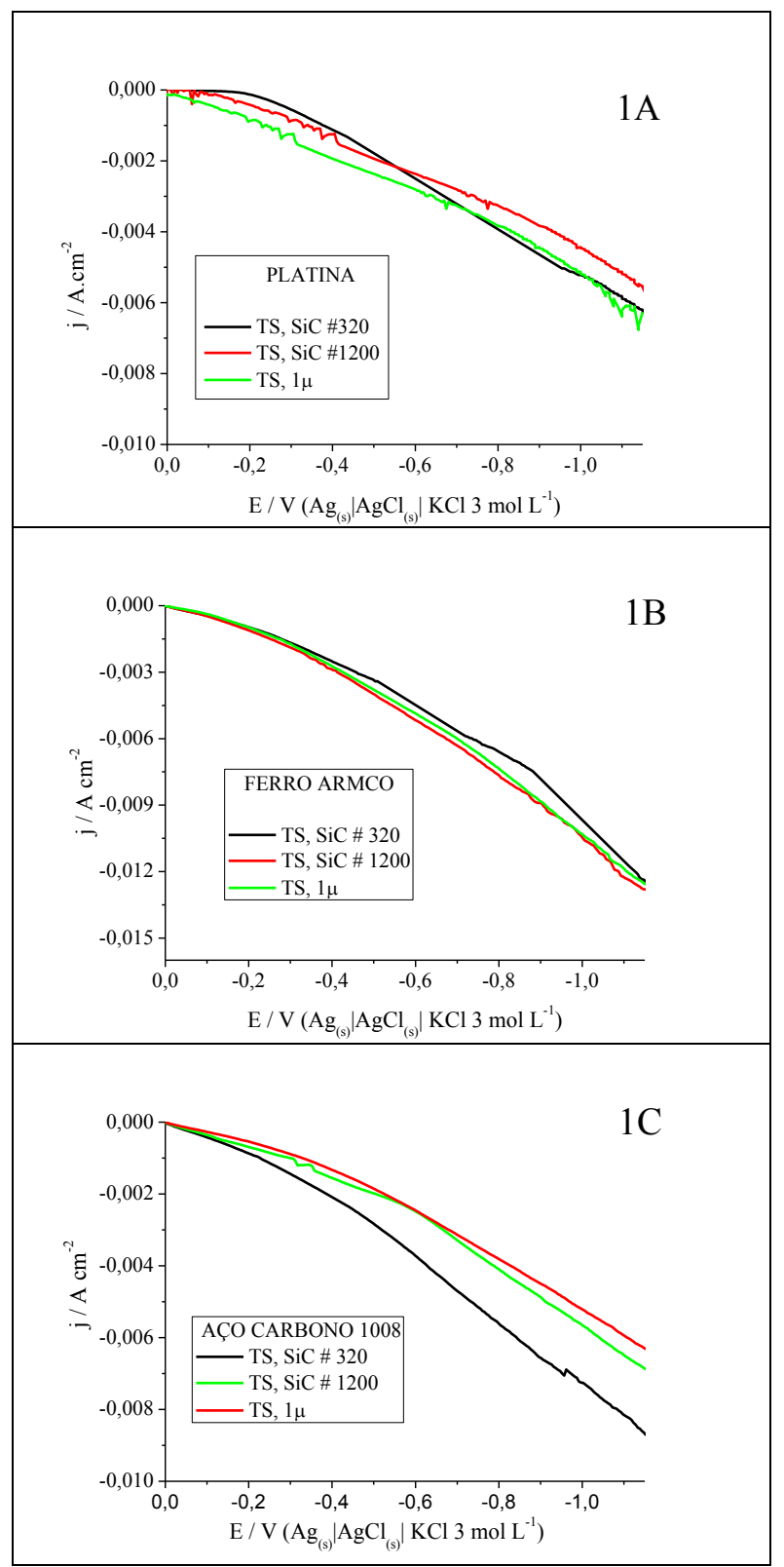

Figura 2: Curvas de PPC, para a platina (1A), ferro Armco (1B) e aço carbono 1008 (1C), polidos até pasta de diamante de $1 \mu \mathrm{m}$ de diâmetro ou lixas de carbeto de silício de \#1200 e \#320, em ácido fórmico $3 \mathrm{~mol} \mathrm{~L}^{-1}$. 


\subsection{Produção de gás hidrogênio em ácido fórmico $3 \mathrm{~mol} \mathrm{~L}^{-1}$}

Na Figura 3 são apresentadas as curvas de PPC para as ligas ferrosas e platina, polidas com lixa de SiC \#320, em meio de ácido fórmico $3 \mathrm{~mol} \mathrm{~L}^{-1}$.

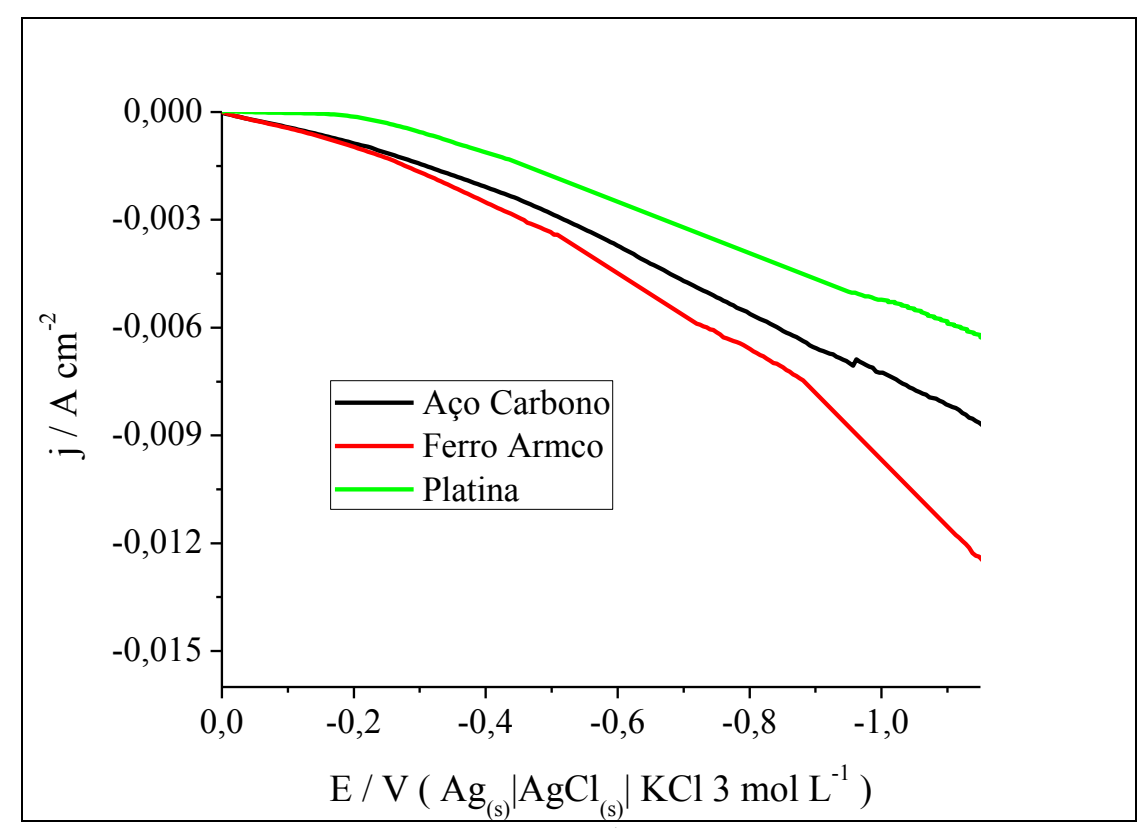

Figura 3: Curvas de PPC obtidas em ácido fórmico $3 \mathrm{~mol} \mathrm{~L}^{-1}$, empregando como eletrodos de trabalho platina e ligas ferrosas com polimento em lixa de $\mathrm{SiC} \# 320$. dica, da figura 3 .

Na tabela 1 são apresentados os resultados dos ensaios de polarização potenciodinâmica cató-

Tabela 1: Valores de estabilização de potencial de circuito aberto $\left(\mathrm{E}_{\mathrm{CA}}\right)$, potencial de desprendimento de hidrogênio $\left(\mathrm{E}_{\mathrm{H} 2}\right)$, e sobrepotencial $\left(\eta_{\mathrm{DH} 2}\right)$, para as ligas ferrosas e platina em ácido fórmico $3 \mathrm{~mol} \mathrm{~L} \mathrm{~L}^{-1}$.

\begin{tabular}{|c|c|c|c|}
\hline Metal & 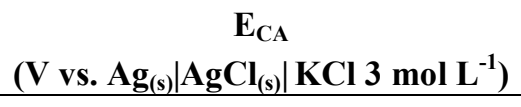 & 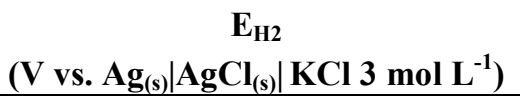 & $\begin{array}{c}\eta_{\mathrm{DH} 2} \\
(\mathrm{~V})\end{array}$ \\
\hline Aço Carbono 1008 & $-0,370 \pm 0,015$ & $-0,300$ & 0,000 \\
\hline Ferro Armco & $-0,320 \pm 0,014$ & $-0,300$ & 0,000 \\
\hline Platina & $-0,150 \pm 0,025$ & $-0,180$ & 0,330 \\
\hline
\end{tabular}


A oxidação do ferro a $\mathrm{Fe}^{2+}$, devido ao meio ácido, pode ser observada nas micrografias ópticas antes e após o ensaio de PPC em ácido fórmico $3 \mathrm{~mol} \mathrm{~L}^{-1}$, conforme figura 4.

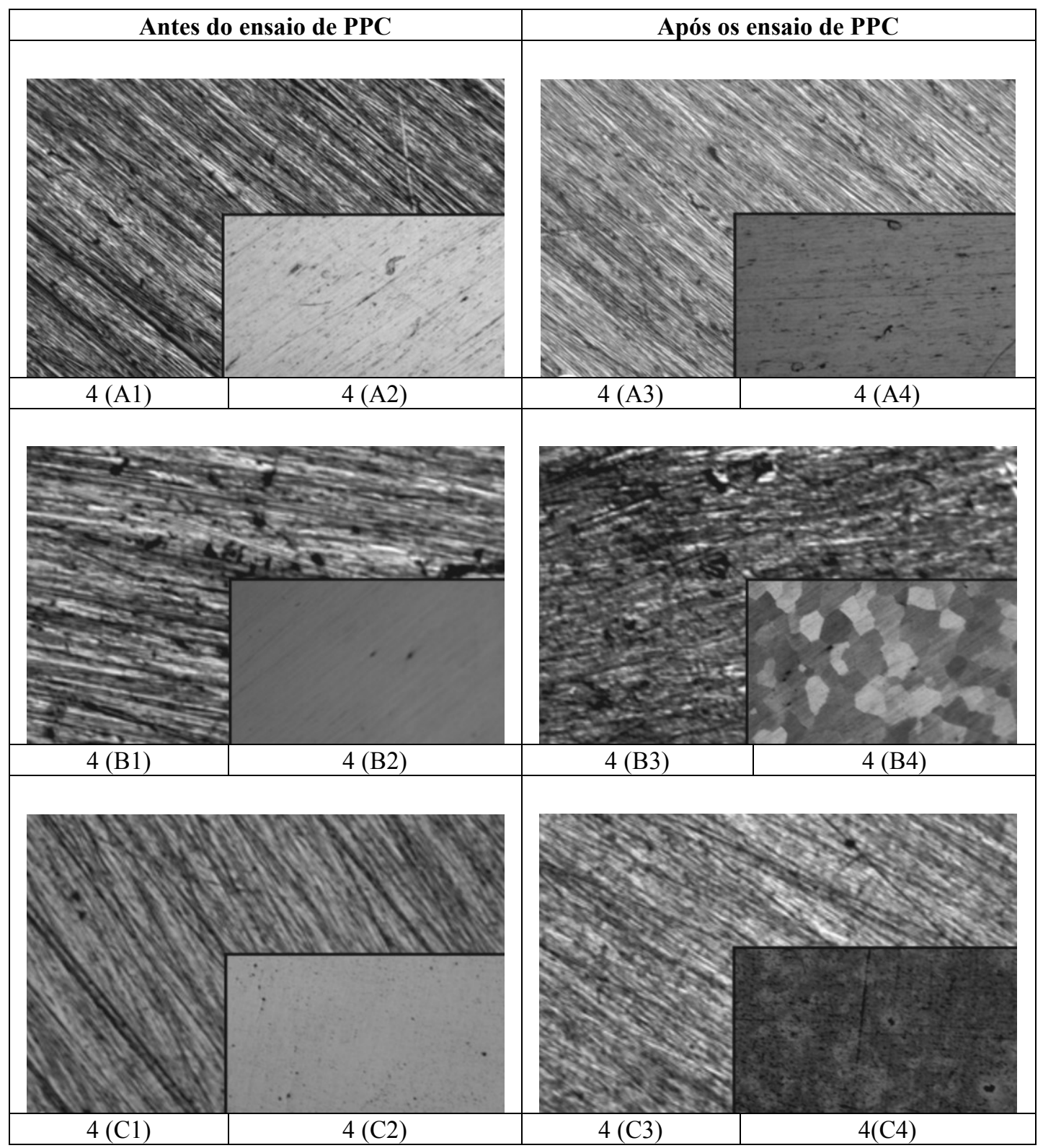

Figura 4: Imagens de microscopia ópticas, com aumento de 100 vezes para os eletrodos de trabalho:

- Polidos com lixa de SiC \#320 - platina 4(A1) e 4(A3), ferro Armco 4(B1) e 4(B3) e aço carbono 4(C1) e 4(C3);

- Polidos com pasta de diamante com partículas $1 \mu \mathrm{m}$ de diâmetro - platina 4(A2) e 4(A4), ferro Armco 4(B2) e 4(B4) e aço carbono 4(C2) e 4(C4). 
Os resultados referentes a técnica de EIE são apresentados nas Figuras 5 e 6.

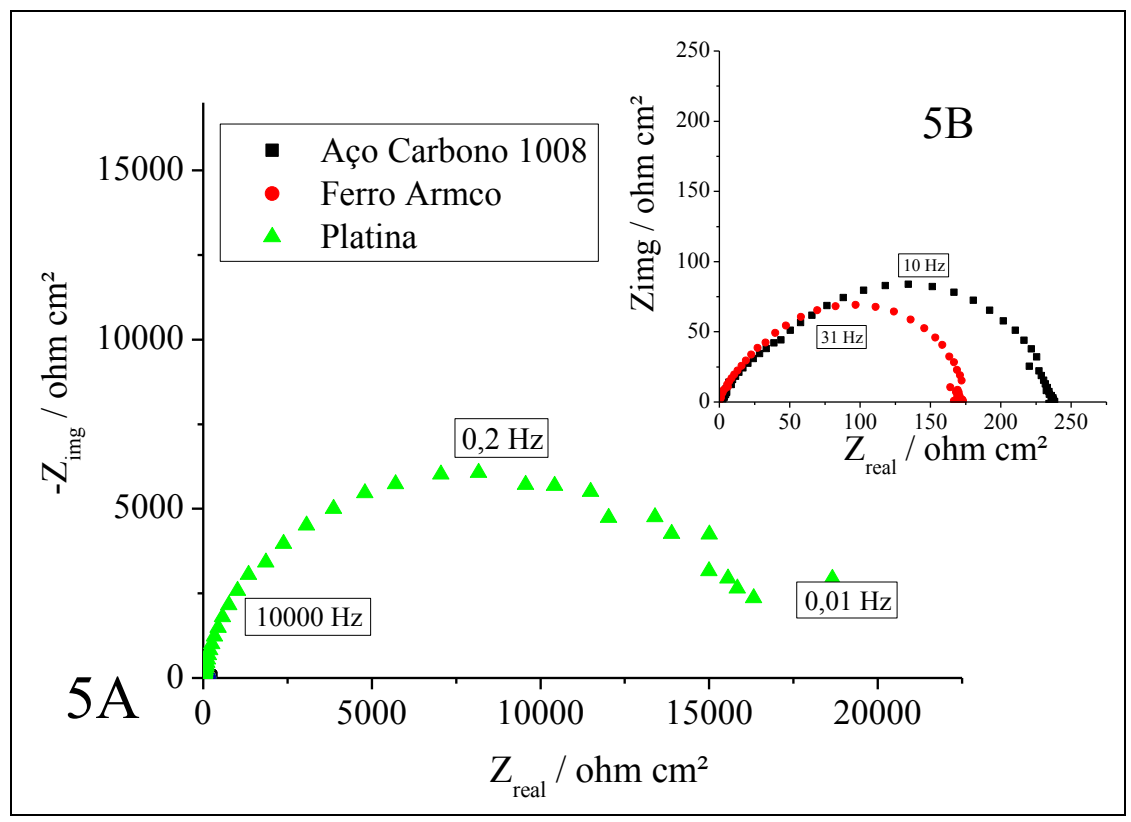

Figura 5: Diagramas de EIE, tipo Nyquist para (A) platina e em (B) para o aço carbono 1008 e ferro Armco, polidos com lixa \#320, em ácido fórmico $3 \mathrm{~mol} \mathrm{~L}^{-1}$.

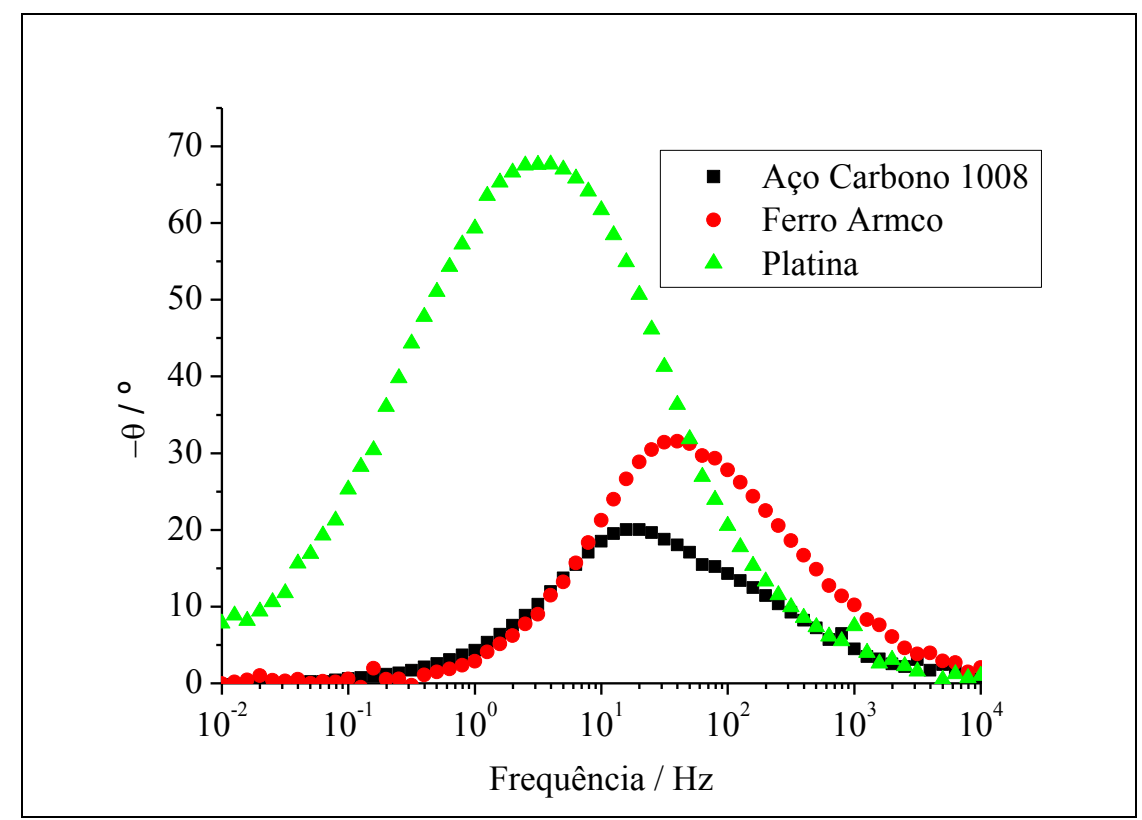

Figura 6: Diagramas de EIE do tipo de Bode-ângulo de fase para o aço carbono 1008, ferro Armco e platina, polidos com lixa \#320, em ácido fórmico $3 \mathrm{~mol} \mathrm{~L}^{-1}$. 
Na Figura 7 são apresentadas as curvas de CR, no potencial de $-1,150 \mathrm{~V}$ vs. $\mathrm{Ag}_{(\mathrm{s})}\left|\mathrm{AgCl}_{(\mathrm{s})}\right| \mathrm{KCl} 3$ mol L ${ }^{-1}$, para as ligas ferrosas e platina.

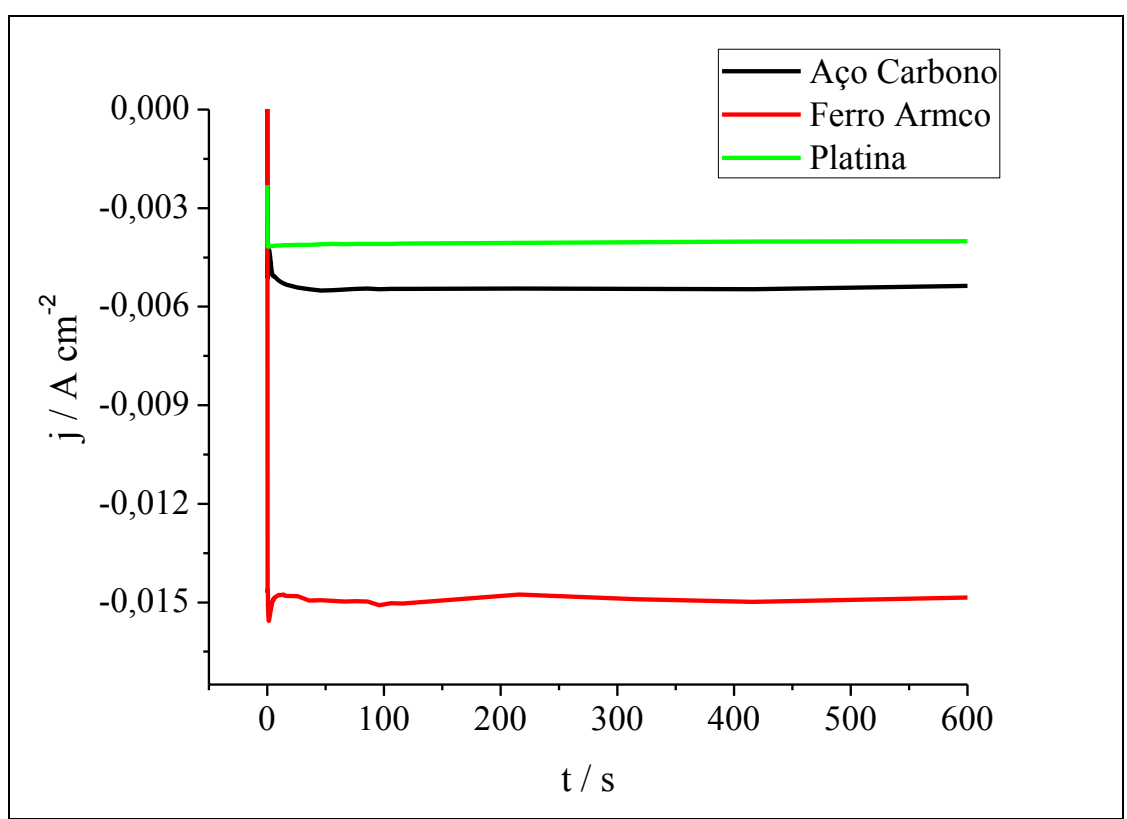

Figura 7: Cronoamperometria para ligas ferrosas e platina previamente polidas com lixa de $\mathrm{SiC} \# 320$ em ácido fórmico 3

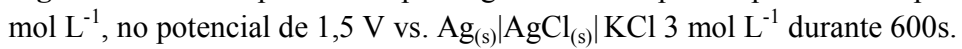

Na tabela 2 são apresentadas as densidades de corrente de estabilização obtidas nos ensaios de cronoamperometria.

Tabela 2: Valores médio de j e número de mol produzido de gás hidrogênio $\left(\mathrm{nH}_{2(\mathrm{~g})}\right)$ em $\mathrm{E}=-1,150 \mathrm{~V} / \mathrm{Ag}_{(\mathrm{s})}\left|\mathrm{AgCl}_{(\mathrm{s})}\right| \mathrm{KCl}$ $3 \mathrm{~mol} \mathrm{~L}^{-1}$, para os diferentes metais estudados.

\begin{tabular}{|c|c|c|}
\hline Metais & $-\mathrm{j}\left(\mathrm{A} \mathrm{cm}^{-2}\right)$ & $\mathrm{nH}_{2(\mathrm{~g})}\left(\mathrm{mol} \mathrm{cm}^{-2}\right)$ \\
\hline Aço Carbono 1008 & $5,40 \times 10^{-3}$ & $1,39 \times 10^{-5}$ \\
\hline Ferro Armco & $1,49 \times 10^{-2}$ & $3,86 \times 10^{-5}$ \\
\hline Platina & $4,00 \times 10^{-3}$ & $1,03 \times 10^{-5}$ \\
\hline
\end{tabular}

\subsection{Produção de gás hidrogênio em ácido fórmico $3 \mathrm{~mol} \mathrm{~L}^{-1}+$ Benzotriazol (BTAH)}

$\mathrm{Na}$ figura 8 são apresentadas as curvas de PPC para as ligas ferrosas e platina em ácido fórmico $3 \mathrm{~mol} \mathrm{~L}^{-1}+$ BTAH $10^{-6} \mathrm{~mol} \mathrm{~L}{ }^{-1}$. 


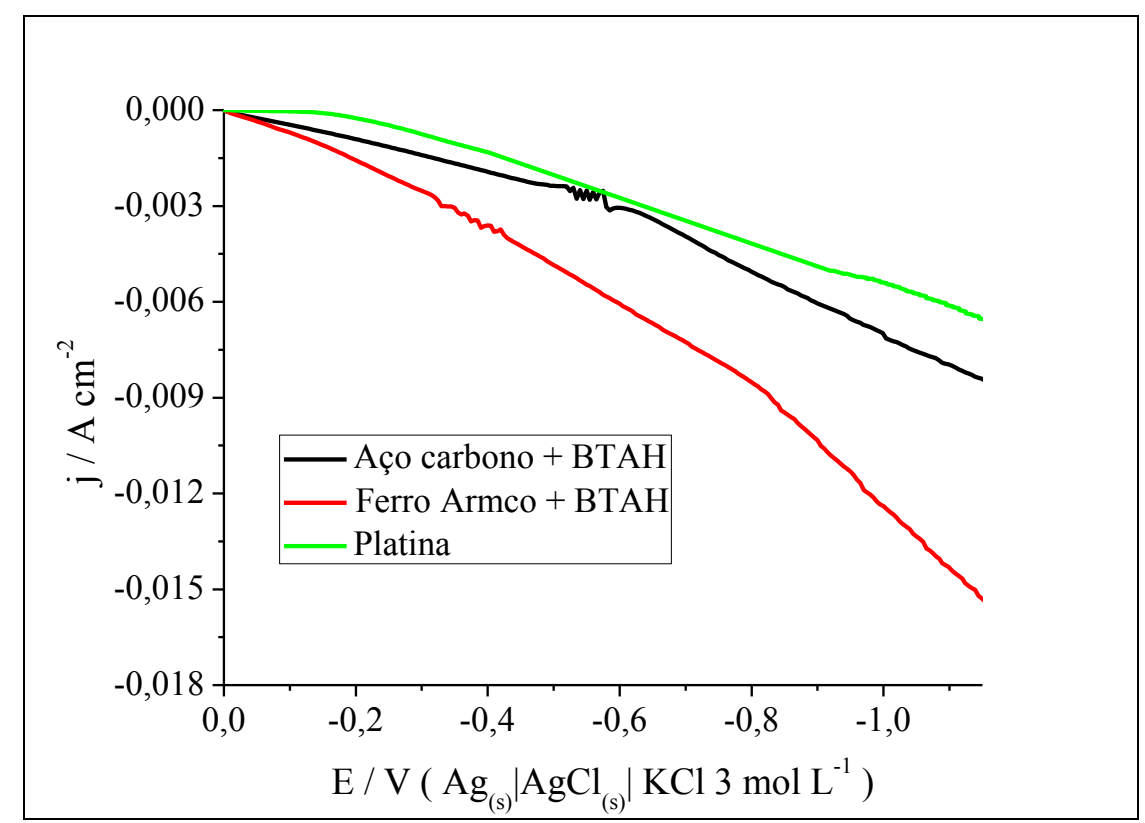

Figura 8: Curvas de PPC para as ligas ferrosas e platina com polimento de \#320, imersas em ácido fórmico $3 \mathrm{~mol} \mathrm{~L}^{-1}+$ BTAH $10^{-6} \mathrm{~mol} \mathrm{~L}^{-1}$.

Na tabela 3 são apresentados os resultados dos ensaios de polarização potenciodinâmica catódica, em acido fórmico + BTAH.

Tabela 3: Valores do potencial de desprendimento de hidrogênio $\left(\mathrm{E}_{\mathrm{H} 2}\right)$ e de estabilização $\left(\mathrm{E}_{\mathrm{est}}\right)$, sobrepotencial $\left(\eta_{\mathrm{DH} 2}\right)$, para as ligas ferrosas e platina em ácido fórmico $3 \mathrm{~mol} \mathrm{~L}^{-1}+\mathrm{BTAH} 10^{-6} \mathrm{~mol} \mathrm{~L}^{-1}$.

\begin{tabular}{c|c|c|c}
\hline Metal & $\mathbf{E}_{\text {est }}(\mathbf{V})$ & $\mathbf{E}_{\mathbf{H} 2}(\mathbf{V})$ & $\boldsymbol{\eta}_{\mathbf{D H} 2}(\mathbf{V})$ \\
\hline Aço Carbono 1008 & $-0,028 \pm 0,006$ & $-0,303$ & 0,275 \\
\hline Ferro Armco & $-0,290 \pm 0,015$ & $-0,324$ & 0,034 \\
\hline Platina & $-0,150 \pm 0,025$ & $-0,180$ & 0,330 \\
\hline
\end{tabular}

Nas figuras 9A a 9D são apresentadas as imagens de microscopia óptica dos materiais estudados antes e após as PPC em ácido fórmico $3 \mathrm{~mol} \mathrm{~L}^{-1}+\mathrm{BTAH} 10^{-6} \mathrm{~mol} \mathrm{~L}^{-1}$.

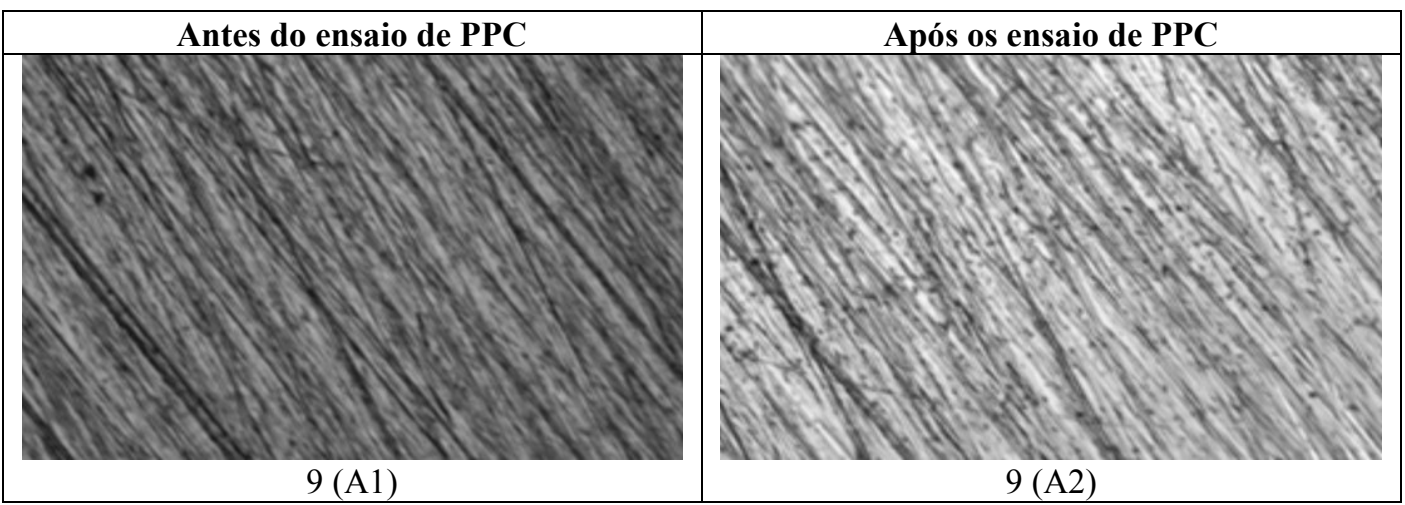




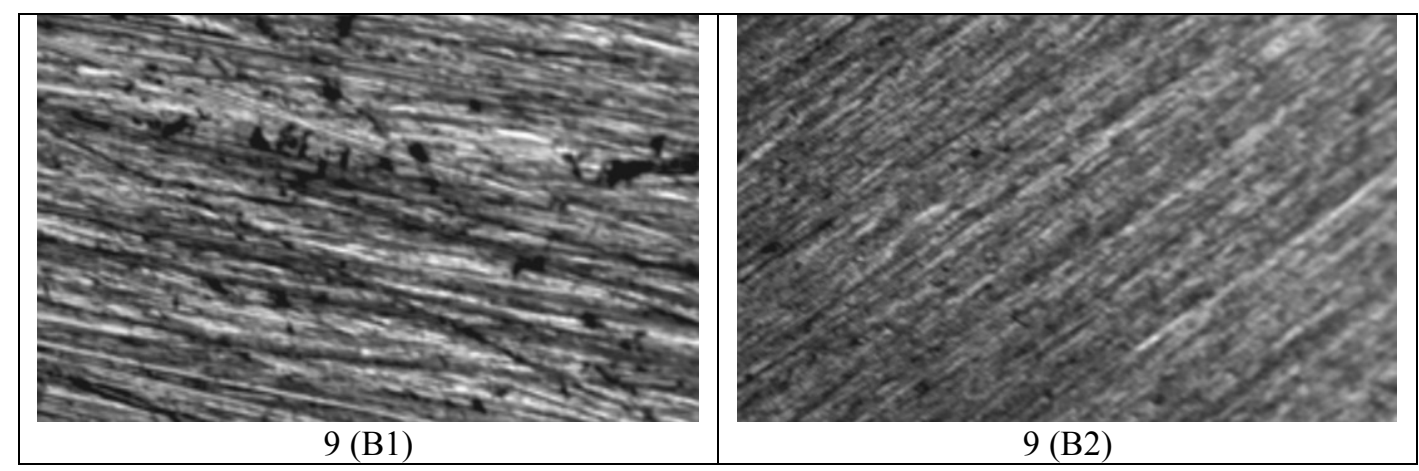

Figura 9: Imagens de microscopia ópticas, com aumento de 100 vezes para os eletrodos de trabalho em ácido fórmico 3 $\mathrm{mol} \mathrm{L}{ }^{-1}+\mathrm{BTAH} 10^{-6} \mathrm{~mol} \mathrm{~L}^{-1}$ :

- Aço carbono 1008 com polimento de lixa de $\mathrm{SiC} \# 320$ - antes da PPC 9 (A1) e após a PPC 9 (A2);

- Ferro Armco com polimento de lixa de SiC \#320 - antes da PPC 9 (B1) e após a PPC 9 (B2).

Na figura 10 são apresentados os ensaios de EIE para as amostras com adição de BTAH.

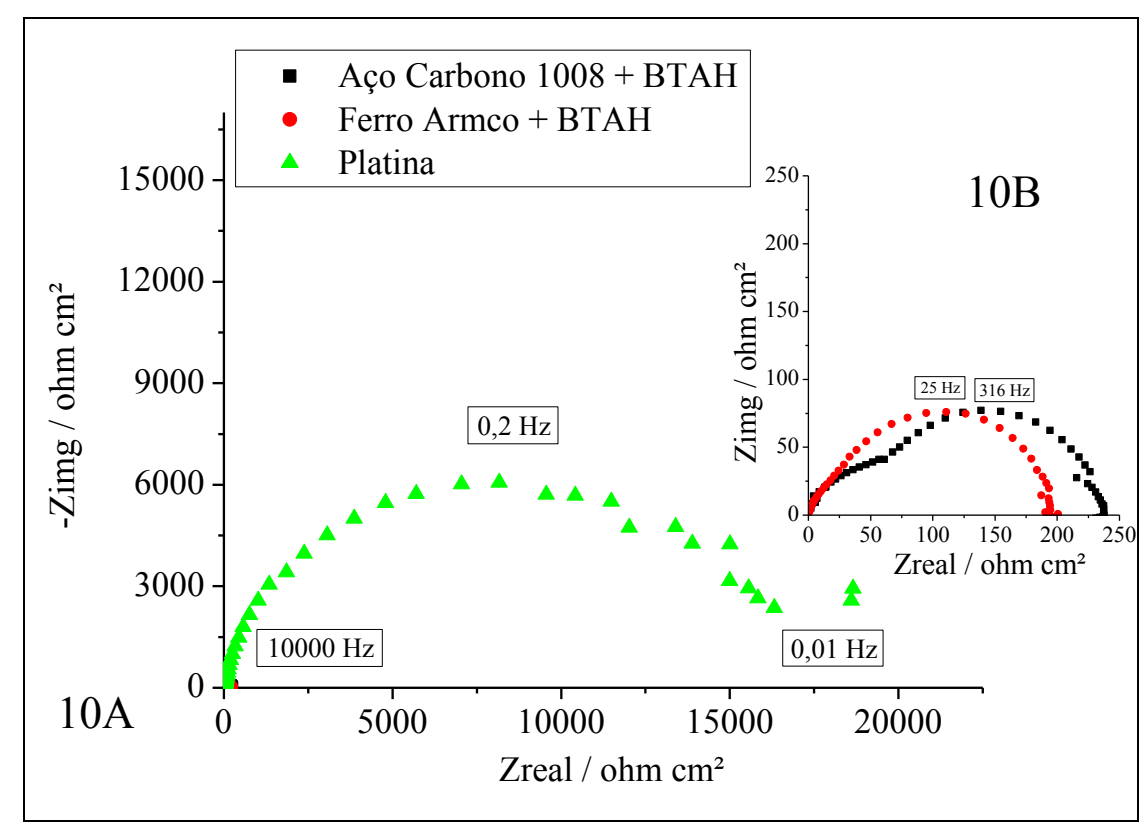

Figura 10: Diagrama de EIE tipo Nyquist das amostras previamente polidas com lixa de $\mathrm{SiC} \# 320$, para (10A) platina em ácido fórmico $3 \mathrm{~mol} \mathrm{~L}^{-1} \mathrm{e}$ (10B) para o aço carbono 1008 e ferro Armco, em ácido fórmico $3 \mathrm{~mol} \mathrm{~L}^{-1}+\mathrm{BTAH} 10^{-6} \mathrm{~mol}$ $\mathrm{L}^{-1}$.

Na figura 11 são apresentados os ângulos de fase de Bode, obtidos para as amostras metálicas em ácido fórmico $3 \mathrm{~mol} \mathrm{~L}^{-1}+\mathrm{BTAH} 10^{-6} \mathrm{~mol} \mathrm{~L}^{-1}$. 


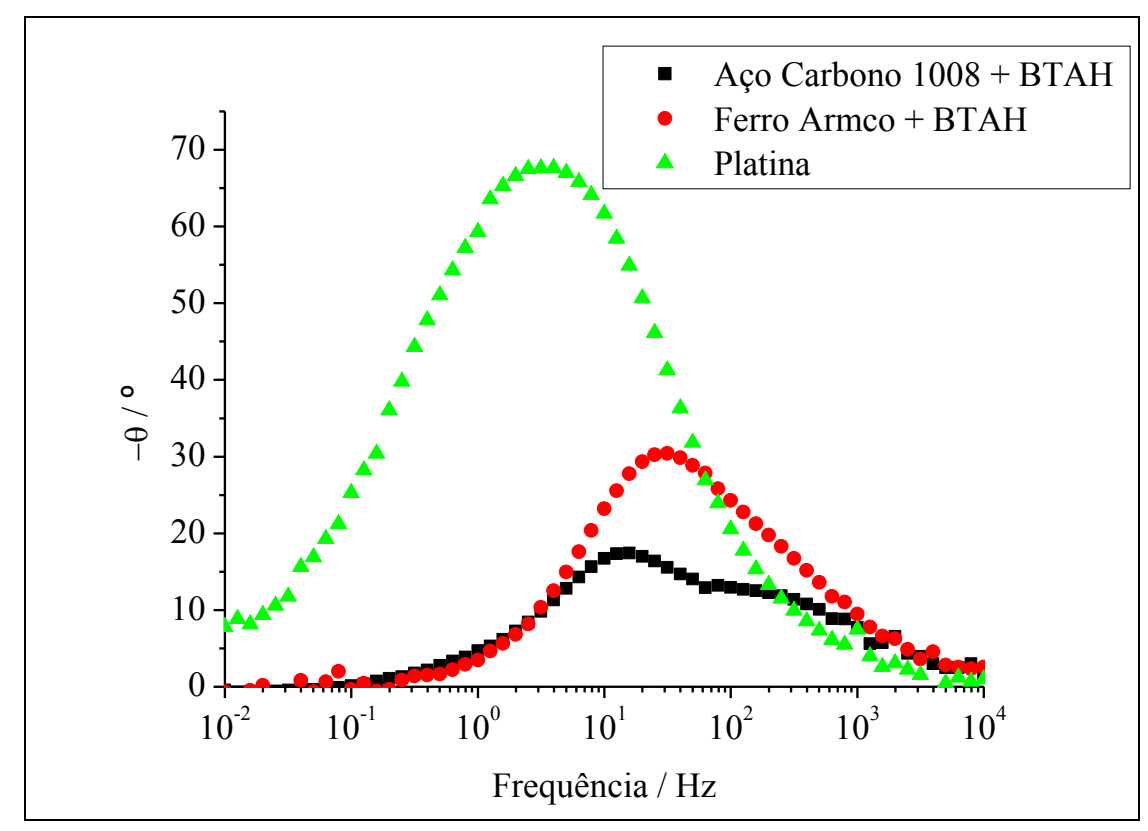

Figura 11: Diagramas de EIE do tipo Bode-ângulo de fase para o aço carbono 1008, ferro Armco e platina, polidos com lixa \#320, em ácido fórmico $3 \mathrm{~mol} \mathrm{~L}^{-1}+\mathrm{BTAH} 10^{-6} \mathrm{~mol} \mathrm{~L}^{-1}$.

Na figura 12 são apresentadas as curvas de $\mathrm{CR}$, no potencial de $-1,150 \mathrm{~V}$ vs. $\mathrm{Ag}_{(\mathrm{s})}\left|\mathrm{AgCl}_{(\mathrm{s})}\right| \mathrm{KCl} 3 \mathrm{~mol}$ $\mathrm{L}^{-1}$, para as ligas ferrosas e platina em ácido fórmico $3 \mathrm{~mol} \mathrm{~L}^{-1}+\mathrm{BTAH} 10^{-6} \mathrm{~mol} \mathrm{~L}^{-1}$.

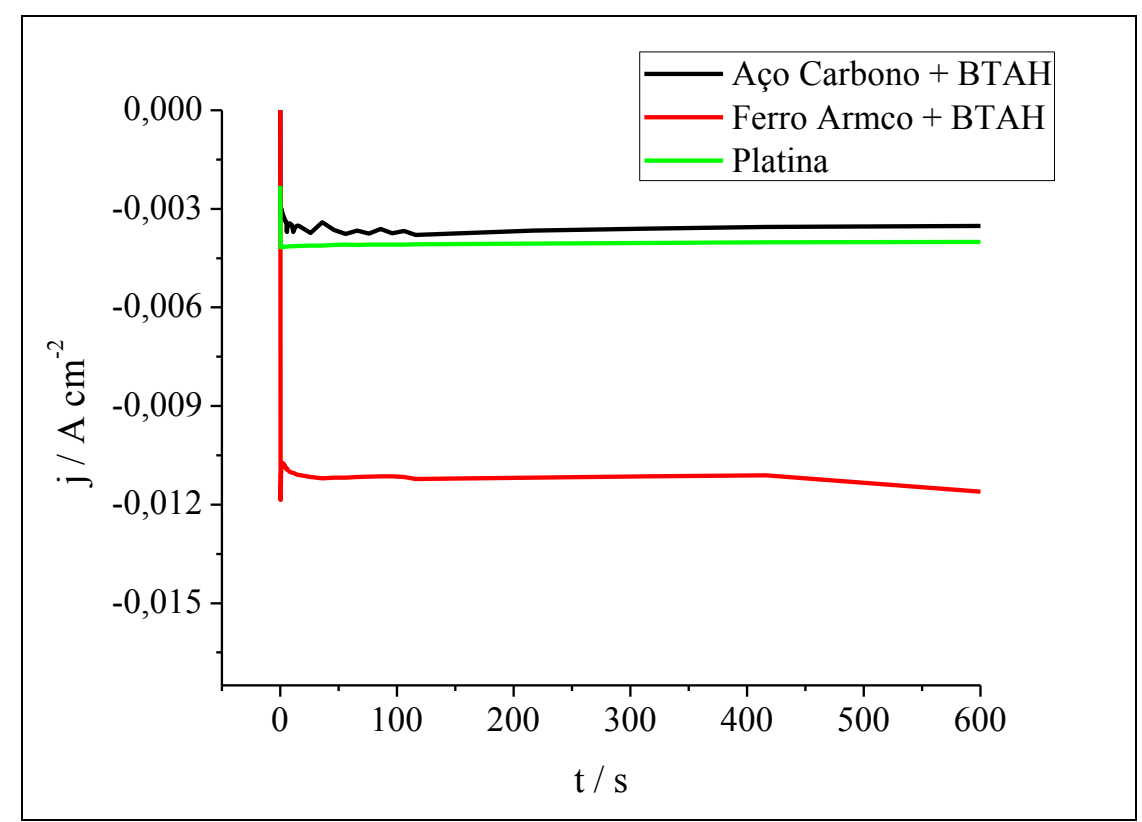

Figura 12: Cronoamperometria para ligas ferrosas em ácido fórmico $3 \mathrm{~mol} \mathrm{~L}^{-1}+[\mathrm{BTAH}]=10^{-6} \mathrm{~mol} \mathrm{~L}^{-1}$ e platina em ácido fórmico $3 \mathrm{~mol} \mathrm{~L}^{-1}$, no potencial de $1,5 \mathrm{~V}$ vs. $\mathrm{Ag}_{(\mathrm{s})}\left|\mathrm{AgCl}_{(\mathrm{s})}\right| \mathrm{KCl} 3 \mathrm{~mol} \mathrm{~L}^{-1}$ durante $600 \mathrm{~s}$. Todas as amostras foram previamente polidas com lixa de $\mathrm{SiC} \# 320$.

Na tabela 4 são apresentadas as densidades de corrente de estabilização obtidas nos ensaios de cronoamperometria da figura 12 . 
Tabela 4: Valores médio de j e números de mol produzido de gás hidrogênio $\left(\mathrm{nH}_{2(\mathrm{~g})}\right)$ para as cronoamperometrias em $\mathrm{E}$ $=-1,150 \mathrm{~V} / \mathrm{Ag}_{(\mathrm{s})}\left|\mathrm{AgCl}_{(\mathrm{s})}\right| \mathrm{KCl} 3 \mathrm{~mol} \mathrm{~L}^{-1}$, para os diferentes metais estudados.

\begin{tabular}{|c|c|c|}
\hline Metais & $-\mathrm{j}\left(\mathrm{A} \mathrm{cm} \mathrm{cm}^{-2}\right)$ & $\mathrm{nH}_{2(\mathrm{~g})}\left(\mathrm{mol} \mathrm{cm}^{-2}\right)$ \\
\hline \multicolumn{3}{|c|}{ Em ácido fórmico $3 \mathrm{~mol} \mathrm{~L}^{-1}+\mathrm{BTAH} 10^{-6} \mathrm{~mol} \mathrm{~L}^{-1}$} \\
\hline Aço Carbono 1008 & $3,6 \times 10^{-3}$ & $9,3 \times 10^{-6}$ \\
\hline Ferro Armco & $1,12 \times 10^{-2}$ & $2,90 \times 10^{-5}$ \\
\hline \multicolumn{3}{|c|}{ Em ácido fórmico $3 \mathrm{~mol} \mathrm{~L}^{-1}$} \\
\hline Platina & $4,0 \times 10^{-3}$ & $1,03 \times 10^{-5}$ \\
\hline
\end{tabular}

\subsection{Estudo de viabilidade financeira da produção de gás hidrogênio em meios de ácido fórmico e áci- do fórmico + BTAH}

Na tabela 5 são apresentados os custos referentes à produção de gás hidrogênio para os meios e materiais estudados em 1 hora de funcionamento da célula de eletrólise.

Tabela 5: Valores de custo e potencia média para os sistemas estudados, considerando-se 1 hora de funcionamento e um valor de $j=4,5 \mathrm{~mA} . \mathrm{cm}^{2}$.

\begin{tabular}{|c|c|c|}
\hline Material & Potência $\left(10^{-3} . W\right)$ & Custo $\left(10^{-6} . \mathrm{R} \$\right)$ \\
\hline \multicolumn{3}{|c|}{ Em ácido fórmico $3 \mathrm{~mol} \mathrm{~L}^{-1}$} \\
\hline Platina & 3,9 & 1,20 \\
\hline Aço Carbono 1008 & 3,1 & 0,90 \\
\hline Ferro Armco & 2,7 & 0,01 \\
\hline \multicolumn{3}{|c|}{ Em ácido fórmico $3 \mathrm{~mol} \mathrm{~L}^{-1}+\mathrm{BTAH} 10^{-6} \mathrm{~mol} \mathrm{~L}^{-1}$} \\
\hline Aço Carbono 1008 & 3,4 & 1,0 \\
\hline Ferro Armco & 2,2 & 0,6 \\
\hline
\end{tabular}

\section{DISCUSSÃO}

Foi observado na figura 2 ausência de variações bruscas de densidade de corrente, para os três materiais estudados, esse comportamento é descrito por vários autores [30-34], porém este fenômeno é fortemente pronunciado nas amostras polidas com lixa \#1200 e pasta de diamante $1 \mu \mathrm{m}$ de diâmetro, devido à formação de bolhas de $\mathrm{H}_{2}(\mathrm{~g})$ que apresentam dificuldade em se dessorver da superfície metálica, consequência da baixa rugosidade da superfície [34].

Após os ensaios de PPC nas condições de TS testadas, foi possível fixar o polimento utilizado durante todo o estudo como sendo a lixa \#320, devido a maior rugosidade da superfície contribuir de forma positiva com a dessorção do gás $\mathrm{H}_{2}$ e influenciar na produção do gás hidrogênio, devido a mudança de área [31-34].

$\mathrm{Na}$ tabela 1, observa-se que quando se compara o $\mathrm{E}_{\mathrm{H} 2}$ dos metais em meio de ácido fórmico, à platina possui o menor potencial de desprendimento de hidrogênio. Entretanto, quando se compara as $\eta \mathrm{DH}_{2}$, observa-se que o aço carbono e o ferro Armco possuem uma sobrepotencial próxima de zero, ou seja, uma menor quantidade de energia é utilizada para a produção do hidrogênio, este fenômeno é relacionado ao processo de oxi-redução, pois o ferro é oxidado de maneira espontânea nas condições estudadas e como consequência desta reação ocorre à redução do hidrogênio, aumentando a densidade de corrente catódica em sobretensões próximas de zero. Estes processos podem ser observados no diagrama de Pourbaix para o ferro na figura 13. Além da oxidação do ferro, a degradação dos eletrodos também pode ocorrer pela permeação do hidrogênio e consequente fragilização do metal [29].

$\mathrm{Na}$ figura 13, é possível prever termodinamicamente quais as espécies que serão formadas em determinadas condições. O ferro oxida-se em uma ampla faixa de potencial e de $\mathrm{pH}$, sendo assim o íon $\mathrm{Fe}^{2+}{ }_{\text {(aq) }}$ produto da oxidação do ferro presente na liga ocorre com maior facilidade. Salienta-se que o $\mathrm{pH}$ inicial das soluções foram igual a 1 e no decorrer da PPC o pH aumenta, atingindo valores de 10 até 11, ou seja, durante o processo ocorre o aumento da alcalinidade do meio. 
Para a platina a sobrepotencial gerada foi de $0,330 \mathrm{~V}$ para desprendimento de hidrogênio, portanto há gasto de $0,330 \mathrm{~V}$ de energia, pois o único processo existente é a transferência de elétrons.

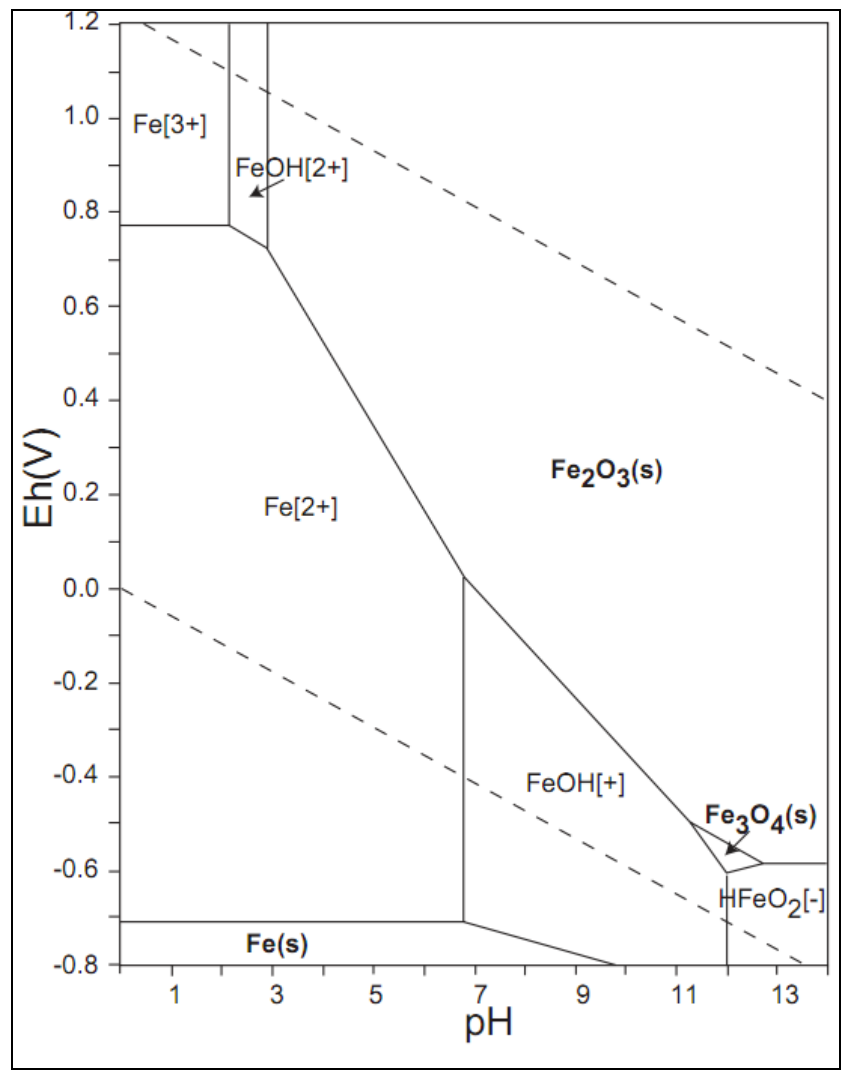

Figura 13: Diagrama de Pourbaix adaptado, para o ferro na faixa de $\mathrm{pH}$ de 0 a 14 e potencial de $-0,8$ a $1,2 \mathrm{~V}$ vs. $\mathrm{H}^{+}{ }_{\text {(aq) }}$ $/ \mathrm{H}_{2(\mathrm{~g})}[27]$.

Pela análise das imagens de microscopia óptica da figura 4 para as ligas ferrosas foi possível verificar o fenômeno de dissolução do ferro previsto pelo diagrama de Pourbaix (figura 3) e pelas maiores correntes de produção de hidrogênio do substrato metálico, principalmente nas amostras polidas até pasta de diamante (figuras 4(B4) e 4(C4)). Ocorre durante a PPC uma oxidação superficial nas amostras de ferro Armco (figura 4(B4)) revelando a estrutura da liga e para o aço carbono a presença de manchas na superfície metálica (figura 4(C4)), indicam o processo de oxidação do metal. Para a platina este comportamento relatado não foi observado, pois a platina apresenta maior resistência à oxidação.

Para comprovação de que a resistência à oxidação é relativamente menor para os substratos de aço carbono e ferro Armco quando comparados à platina foi utilizado a técnica de EIE, e os resultados destes ensaios estão apresentados nas Figuras 5 e 6 .

De acordo com as curvas de Nyquist apresentadas nas Figuras 5A e B, pode-se confirmar os resultados propostos pelas microscopias ópticas e pelo diagrama de Pourbaix. A platina apresenta maior resistência à polarização, ou seja, sofre menor ataque do ácido, que os substratos aço carbono e ferro Armco, na ordem de 100 vezes. Desta maneira durante a produção de hidrogênio a platina não sofrerá oxidação, como o ferro Armco e o aço carbono, porém esta corrosão auxilia a produção de hidrogênio.

De acordo com os diagramas de bode apresentados na figura 6, a platina apresenta um ângulo de fase na região entre $1-10 \mathrm{~Hz}$ o que indica transferência de carga na superfície do eletrodo. Para o aço carbono e ferro Armco o ângulo de fase esta deslocado para valores de frequências mais elevadas e em uma faixa maior, sugerindo que existe mais do que uma constante de tempo, entre $10-100 \mathrm{~Hz}$. A primeira próxima a frequência de $10 \mathrm{~Hz}$ indicando que há adsorção de espécies na superfície dos eletrodos, possivelmente água ou o próprio gás hidrogênio [29], já a segunda próximo a frequências de $100 \mathrm{~Hz}$, pode ser associada a formação de óxidos [35]. Outro fenômeno observado esta relacionado a valor do ângulo de fase, que para a platina foi maior que para as ligas ferrosas, isso indica um comportamento capacitivo elevado, ou seja, o emparelhamento de cargas sobre a superfície ocorre de maneira mais pronunciada na platina $[35,36]$.

A partir das informações obtidas do diagrama de Pourbaix e das medidas de EIE, foi proposto um me- 
canismo para produção de gás hidrogênio para as ligas ferrosas que além da corrente catódica forçada existe a oxidação do ferro, como apresentada nas reações 1,2 e 3.

Cátodo:

$$
\begin{aligned}
& \mathrm{Fe}_{(s)} \rightarrow \mathrm{Fe}_{(a q)}^{2+}+2 e^{-} \\
& 2 \mathrm{H}_{2} \mathrm{O}+2 e^{-} \rightarrow \mathrm{H}_{2(g)}+2 \mathrm{OH}_{(a q)}^{-}
\end{aligned}
$$

Ânodo:

$$
\mathrm{HCOOH}_{(a q)}+2 \mathrm{OH}_{(a q)}^{-} \rightarrow \mathrm{H}_{2} \mathrm{O}+\mathrm{CO}_{2(g)}+2 e^{-}
$$

De acordo com os resultados já apresentados nas ligas ferrosas há oxidação espontânea do ferro, conforme a reação 1 e confirmado por dados termodinâmicos apresentados no diagrama de Pourbaix (Figura13), e ao mesmo tempo ocorre a produção de gás hidrogênio (reação 2), elevando o pH do meio, este último resultado sendo observado utilizando-se medidas de pH simultâneas ao ensaio de PPC [26, 31-34]. Na superfície da platina, há somente a troca de elétrons então, a reação 2 é a única a ocorrer no cátodo. Tanto para as ligas de ferro quanto para platina a reação 3 representa o processo que ocorre no ânodo.

Na figura 7, utilizando-se dos dados de densidade de corrente no período de tempo de 100s a 600s e as Leis de Faraday que estão apresentados na tabela, 2 verifica-se que em meio de ácido fórmico com o eletrodo de ferro Armco foi possível produzir cerca de 3 vezes mais hidrogênio do que o obtido com a platina. Este fenômeno é relacionado a um processo de oxi-redução, que ocorre paralelo a reação de produção de hidrogênio, devido a corrente catódica forçada (PPC), o ferro é oxidado de maneira espontânea nas condições estudadas $(\mathrm{pH}<1$ e $\mathrm{E}<0 \mathrm{~V})$ e como consequência, desta reação existe a redução do hidrogênio, assim pode-se inferir que existem duas fontes para a produção de gás hidrogênio, fato que não acontece no eletrodo de platina. Salienta-se que este fenômeno degrada o eletrodo, como já relatado.

As curvas cronoamperométricas apresentadas na figura 7 foram realizadas, para determinar a quantidade de gás hidrogênio, produzido durante $600 \mathrm{~s}$, aplicando-se $-1,150 \mathrm{~V}$ de potencial, este valor foi escolhido devido a possibilitar uma maior corrente catódica e consequentemente maior produção de $\mathrm{H}_{2(\mathrm{~g})}$.

Na figura 8 e na tabela 3, observa-se que quando se adiciona o BTAH ao eletrólito, o gasto de energia do aço carbono e do ferro Armco, teve valores diferentes de zero, diferentemente do que foi observado, quando se utiliza somente o acido fórmico (tabela 1), entretanto, os valores de sobrepotencial ainda são menores que o obtido para a platina. Este comportamento é explicado pela adsorção do BTAH sobre a superfície, assim por seu caráter anticorrosivo amplamente estudado, não permite com a mesma eficiência a espontaneidade do processo de oxidação do ferro, contribuindo para a minimização da produção de gás hidrogênio, visto que a produção está associada também a oxidação do eletrodo, como descrito anteriormente e consequentemente é necessária uma quantidade maior de energia para o processo inicie [30].

Nas imagens de microscopia óptica, apresentados na figura 9, pode-se observar que o desgaste do material devido ao processo oxidação do $\mathrm{Fe}_{(\mathrm{s})}$, durante a polarização, não altera significativamente a superfície das amostras. Este comportamento também foi confirmado nos ensaios de EIE, apresentados na figura 10.

De acordo com os diagramas tipos Nyquist das figuras 10A e B, observa-se que a adição de BTAH não mudou o perfil apresentado pelas amostras (figura 5), ou seja, a platina ainda possui maior resistência a polarização que os demais materiais estudados. Quando se compara os resultados das figuras 5B e 10B para o ferro Armco, a presença de BTAH altera a resistência a polarização, para valores maiores, fato que pode ser explicado pela formação de um complexo de $\mathrm{Fe}(\mathrm{BTA})_{2}$, sobre a superfície metálica, o que proporciona uma aumento na resistência a oxidação [29].

Quando é analisado os resultados referentes dos diagramas de Nyquist das figuras 5B e 10B, observase que o máximo de impedância imaginária obtida, que está associada a capacitância da dupla camada elétrica ocorre em frequências elevadas quando adiciona-se BTAH, para as ligas ferrosas, ou seja, houve uma mudança na superfície do substrato metálico, provavelmente pela adsorção do BTAH, que pode ocorrer pela formação de complexos [28-29].

Observa-se nos diagramas de ângulo de fase de Bode, apresentadas na figura 11, em comparação aos ensaios da figura 6 que para o aço carbono 1008, existem a presença de dois ângulos de fase, o primeiro na região de $10 \mathrm{~Hz}$, indicando transferência de carga na superfície do eletrodo e outro menos pronunciado, próximo a $100 \mathrm{~Hz}$, sugerindo a presença de uma camada de óxido ou até mesmo do complexo de $\mathrm{Fe}(\mathrm{BTA})_{2}$ na 
superfície do eletrodo. Já para o ferro Armco não houve diferenças significativas no ângulo de fase na presença ou ausência de BTAH, ainda que para este metal a capacitância da dupla camada elétrica tenha ocorrido em frequências mais elevadas [28-29].

Na tabela 4, que quando se utiliza o BTAH juntamente com o ácido fórmico é possível produzir no eletrodo de ferro Armco duas vezes mais hidrogênio que para a platina.

Ao comparar a tabela 2 com a tabela 4 para as ligas ferrosas, destaca-se que a produção de hidrogênio diminui cerca de $30 \%$ quando se adiciona o BTAH, provavelmente devido a adsorção do BTAH na superfície do ferro.

Para o estudo de viabilidade financeira foi realizada uma pesquisa para se obter o preço médio da energia, cujo valor é 0,2985 reais por $\mathrm{kWh}$, este valor sem impostos [35]. Para o cálculo também foi considerado os resultados referentes às curvas de PPC, em uma densidade de corrente fixada em 4,5 mA.cm² e foi utilizado a sobrepotencial de cada material e o meio estudado para atingir este valor de $j$.

De acordo com a tabela 5 observa-se que o menor custo é referente ao ensaio com o Ferro Armco em ácido fórmico $3 \mathrm{~mol} \mathrm{~L}^{-1}$, para esta situação a economia é de cerca de 120 vezes quando comparado com a platina. Salienta-se que foi considerada apenas a produção de gás hidrogênio, ou seja, o valor do eletrodo de aço carbono não foi considerado, o que acarreta em maior economia, devido ao alto custo da platina. Ressalta-se que o BTAH atua para o ferro Armco como inibidor da reação de desprendimento de hidrogênio e no aço carbono como catalisador.

Além dos custos de energia elétrica deve-se considerar a substituição dos eletrodos ferrosos que se oxidarem, e o lucro da venda da lama do óxido de ferro para produção de soluções de tratamento de superfície metálicas [36].

\section{CONCLUSÕES}

O emprego de ligas ferrosas como aço carbono 1008 e ferro Armco como alternativa a platina para produção de gás hidrogênio é viável eletroquimicamente, em ácido fórmico e ácido fórmico + BTAH. A produção de gás hidrogênio utilizando-se ligas de ferro foi superior à quantidade produzida pela platina em média em $30 \%$. A presença do BTAH em solução aumentou à resistência a corrosão das ligas ferrosas, porém minimizou a produção de hidrogênio. Em termos econômicos a utilização do aço carbono 1008 como eletrodo em ácido fórmico $3 \mathrm{~mol} \mathrm{~L}^{-1}$ mostra uma economia de aproximadamente $50 \%$, quando comparado aos custos de energia do processo eletrolítico, quando se emprega a platina.

\section{AGRADECIMENTOS}

Ao CNPq e a CAPES pelo apoio financeiro.

\section{BIBLIOGRAFIA}

[1] BILGILI, M., OZBEK, A., SAHIN, B., et al. "An overview of renewable electric power capacity and progress in new technologies in the world”, Renewable and Sustainable Energy Reviews, v.49, pp. 323-334, 2015.

[2] PEREIRA, M. G., CAMACHO, C. F., FREITAS, M. A. V., et al. The renewable energy market in Brazil: Current status and potential. Renewable and Sustainable Energy Reviews, v.16, p.3786-3802, 2012.

[3] OMRI, A., NGUYEN, D. K. On the determinants of renewable energy consumption: International evidence, Energy, v.72, p. 554-560, 2014.

[4] MIRANDA, P. E. V. “A energia do hidrogênio”, Matéria (Rio J.), v. 17, n. 1, 2012.

[5] MIRANDA, P. E. V. "Materiais para energia do hidrogênio", Matéria (Rio J.), v. 14, n. 3, 2009.

[6] MEDEIROS, E. F., Hidrogênio energético no Brasil: subsídios para políticas de competitividade 20102025. 1 ed., Brasília, Centro de Gestão e Estudos Energéticos (CGEE), 2010.

[7] TICIANELLI, E. A., GONZALEZ R. “Células a Combustível: uma alternativa promissora para a geração de eletricidade”, Química Nova. v. 12, pp. 268-272, 1989.

[8] WENDT, H., GOTZ, M. “Tecnologia de células a combustível”, Química Nova. v. 23, pp.538-546, 2000.

[9] ZHANG, X., SHEN, Z. "Carbon fiber paper for fuel cell electrode”, Fuel, v. 81. pp. 2199-2201, 2002. 
[10] HERDEM, M. C., FARHAD, S., DINCER, I., et al. "Thermodynamic modeling and assessment of a combined coal gasification and alkaline water electrolysis system for hydrogen production", International Journal of Hydrogen Energy, v.39, pp.3061-3071, 2014.

[11] MONNIER, J., ZANGH, Y., McFARLAN, A. Production of hydrogen from oxygenated hydrocarbons, US0027169, 2011.

[12] HUANG, C. Electrochemical method for producing and storing hydrogen by the redox of zinco and water, US0190781, 2008.

[13] PARTHASARATHY, P., NARAYANAN, K. S. "Hydrogen production from steam gasification of Biomass: Influence of process parameters on hydrogen yield - A review", Renewable Energy, v. 66, p.570 579,2014

[14] QUITETE, C. P. B., SOUZA, M. M. V. M. "Remoção do Alcatrão de correntes de gaseificação de biomassa: processos e catalisadores”, Química Nova, v. 37, n. 4, pp.689-698, 2014.

[15] SÁ, L. R. V., CAMMAROTA, M. C., LEITÃO, V. S. F. "Produção de hidrogênio via fermentação anaeróbia - aspectos gerais e possibilidade de utilização de resíduos agroindustriais brasileiros", Quimica Nova, v. 37, n. 5, pp.857-867, 2014.

[16] AZWAR, M. Y., HUSSAIN, M. A., ABDUL-WAHAB, A. K. "Development of biohydrogen production by photobiological, fermentation and electrochemical processes: A review", Renewable and Sustainable Energy Process, v.31, p.158-173, 2014.

[17] GHIMIRE, A., FRUNZO, L., PIROZZI, F., et al., "A review on dark fermentative biohydrogen production from organic biomass: Process parameters and use of by - products", Applied Energy, v. 144, p.73-95, 2015.

[18] TOMEN, F. E. Produção de gás hidrogênio com aço inoxidável 254 em ácido fórmico, glicerina e íons OH-. 2014. 62p. Dissertação de M.Sc., Universidade Estadual do Centro-Oeste, UNICENTRO, Guarapuava $-\mathrm{PR}$.

[19] BHANDARI, R., TRUDEWIND, C. A., ZAPP, P. "Life cycle assessment of hydrogen via electrolysis a review”, Journal of Cleaner Production, v.85, pp.151-163, 2014.

[20] NAN, J., HSU, T., LIN, H. Method for producing hydrogen by using different metals, United States Patent US7.704.484, 2010.

[21] ZOUHRI, K., LEE, S. Y. "Evaluation e Optimization of the alkaline water electrolysis ohm polarization: Exergy Study”, International Journal of Hydrogen Energy, v.41, n.18, pp. 7253- 7263, 2016.

[22] FOSTER, M. G. S., ARAUJO, S. C. S., SILVA, M. J. Estruturação da economia do hidrogênio no Brasil, In: Seminários Temáticos para a $3^{a}$ Conferência Nacional de C, T\& I, 20, pp. 755-780, junho de 2005.

[23] HERRMANN, H. W., KOVALSKI, G., CAPARICA, R., et al. "Analysis of gases released in the glycerin microbiological fermentation in dextrose medium”, In: Méndez - Vilas, A. Materials and processes for energy: communicating current research and technological developments, 1ed., Badajoz, Spain, Formatex Research Center, 2013.

[24] LOGAN, B. Electrohydrogenic reactor for hydrogen gas production. US7.922.878, 2011.

[25] ZOUHRI, K., LEE, S. ANDRADE, R.D.A. Calor de combustão de blendas do tipo diesel/biodiesel e diesel/bio-óleo.Tese de M. Sc., IQ/UnB, Brasília, DF, Brasil, 2009.

[26] GUO, W.L., LI, L., LI,L.L., et al. "Hydrogen production via electrolysis of aqueous formic acid solutions”, International Journal of Hydrogen Energy, v. 36, ed.16, pp. 9415-9419, 2011.

[27] POURBAIX, M. Lições de corrosão electroquímica. $3^{\mathrm{a}}$ ed., Bruxelas, CEBELCOR, 1987.

[28] SILVA, D. K., et al. "Benzotriazole and tolytriazole as corrosion inhibitors of carbon steel 1008 in sulfuric acid”, Port. Electrochim. Acta, v.24, n.3, pp. 323-335, 2006.

[29] RODRIGUES, P. R. P. O benzotriazol como inibidor de corrosão para ferro e ligas ferrosas em meios de ácido sulfúrico., Tese de D. Sc. IQ/USP, São Paulo, SP, Brasil, 1997.

[30] HOLZLE, L. R. B. Comportamento eletroquímico do alumínio em misturas etilenoglicol-água. Efeito da adição de agentes quelantes., Tese de D. Sc.. IQ/UFRGS. Porto Alegre, RG, Brasil, 2005. 
[31] GALlinA, A. L. Produção do gás hidrogênio utilizando glicerina e eletrodos metálicos de baixo custo. Tese de D. Sc, Universidade Estadual do Centro Oeste, UNICENTRO, PR, Brasil , 2014.

[32] GALlinA, A. L., DIAS, B. V., RODRIGUES, P. R. P. “Aplicação de aços inoxidáveis na geração de hidrogênio como combustível”, Revista Virtual de Química, v. 6, n.2, p.224-234, 2014.

[33] DIAS, B. V., MATOS, A. P. C., GALINA, A. L. et al., Hydrogen gas production employing brass electrode in formic acid with and without organic compounds. In: Materials and processes for energy: communicating current research and technological developments, Badajoz, Formatex Research Center, v.1, pp. 141$145,2015$.

[34] GALINA, A. L., DIAS, B. V., RODRIGUES, P. R. P. The use of stainless steel 254 to produce hydrogen. Materials and processes for energy: communicating current research and technological developments, 1ed., Badajoz, Formatex Research Center, v. 1, pp. 464-469, 2013.

[35] MATOS, L. A. C. Estudo da corrosão de ligas ferrosas em diesel e biodiesel, Dissertação de M.Sc., UNICENTRO/PR, Guarapuava, PR, Brasil, 2013.

[36] OLIVEIRA, M. F. Processo de fosfatização a base de ferro ii contendo tolitriazol para o aço carbono, Dissertação de M.Sc, UNICENTRO/PR, Guarapuava, PR, Brasil, 2008.

[37] ANEEL, http://www.aneel.gov.br/area.cfm?idArea=493. Acessado em setembro de 2013 